\title{
Pedagogía del amor y PNL para la educación integral. El desarrollo humano integral de la persona
}

\section{Pedagogy of love and NLP for comprehensive education. The integral human development of the person}

\author{
Wilfredo Montenegro Carrasco* \\ Escuela Profesional de Psicología, \\ Universidad de San Martín de Porres, Perú
}

\section{Resumen}

La pedagogía del amor, denominada también pedagogía afectiva o de la felicidad, es una exigencia imprescindible en el desarrollo de una educación integral, la cual exige tratar al otro como persona, valorando su dignidad, su identidad, su forma de ser, sus sentimientos, etc. Las estrategias de la pedagogía del amor son estímulos positivos que arrancan de la mente y del corazón de cada joven una respuesta positiva en las diversas circunstancias de la vida académica y social. Así como, impulsa al docente a enseñar con la razón pero sobre todo con el corazón.

Desde la psicología y las ciencias de la mente humana, la programación neurolingüística (PNL) cumple un rol fundamental en la pedagogía del amor. Sus técnicas y estrategias son claves en la consolidación de la buena comunicación y el logro del aprendizaje, conocimientos y actitudes significativas. El rendimiento académico y el comportamiento de los estudiantes, son efectos directos de la pedagogía del amor. En consecuencia, son los padres de familia y maestros quienes cumplen un rol fundamental en la formación integral de las nuevas generaciones.

Palabras clave: pedagogía del amor, pedagogía afectiva, pedagogía de la felicidad, PNL, calidad del rendimiento académico, calidad del comportamiento.

Este es un artículo Open Access bajo la licencia Creative Commons Atribución-NoComercial-Compartirlgual 4.0

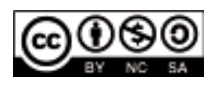




\begin{abstract}
The pedagogy of love, also called affective pedagogy or happiness, is an essential requirement in the development of an education integral, which requires treating the other as a person, valuing their dignity, their identity, their way of being, their feelings, etc. The strategies of pedagogy of love are positive stimuli that start from the mind and heart of each young person a positive response in the various circumstances of life academic and social. As well as, it encourages the teacher to teach with reason but especially with the heart.
\end{abstract}

From the psychology and sciences of the human mind, programming neurolinguistics (NLP) plays a fundamental role in the pedagogy of love. Its techniques and strategies are key in the consolidation of good communication and the achievement of learning, knowledge and attitudes significant. The academic performance and behavior of students, are direct effects of the pedagogy of love. In consecuense, it is the parents and teachers who play a fundamental role in the integral formation of the new generations.

Keywords: pedagogy of love, affective pedagogy, pedagogy of happiness, NLP, quality of academic performance, quality of behavior.

\title{
Introducción
}

La formación de la persona humana es fruto de una educación integral, actualmente ausente en las políticas y sistemas educativos. Esta educación integral se caracteriza por la calidad del rendimiento académico y el comportamiento. La calidad del rendimiento académico y el comportamiento son el fruto de una serie de condiciones, tales como una adecuada metodología, pedagogía del docente, ambiente adecuado, hábitos de estudio, pero sobre todo, del afecto (pedagogía del amor) recibido tanto en la familia como en los ambientes educativos. El afecto es un poderoso motivador estratégico para alcanzar la esperada calidad del rendimiento académico y el comportamiento, y por ende la formación integral de la persona. Esta motivación, «la pedagogía del amor, genera vínculos de confianza, aporte significativo a la educación integral de la persona humana» (Vanga \& Fernández, 2016, p. 33); sin embargo, esta perspectiva es ajena a los intereses de la esperada educación integral. 


\section{Perfil de las nuevas generaciones y la postmodernidad}

Las nuevas generaciones se caracterizan por su frialdad e indiferencia frente al rendimiento académico y el comportamiento. La calidad y excelencia en los logros del rendimiento y la conducta parecen ser cosa del pasado, lo propio de estos tiempos es el desorden, la informalidad, la mediocridad, entre otros. El reduccionismo del mercado a la competitividad ha sido adoptado por las políticas educativas actuales. La calidad del rendimiento académico y el comportamiento fruto de este reduccionismo solo se centra en la búsqueda del hombre meramente productivo y calculador. Estudiantes que dejan de lado el verdadero propósito de su educación a cambio de una nota aprobatoria. El cálculo es aprobar como sea. Sin duda estamos en una situación donde el hombre mide su valor más por lo que tiene, que por lo que es o debe ser: persona humana. La mediocridad en las relaciones humanas, la pérdida de la conciencia, son el efecto del reduccionismo materialista aplicado en el ámbito educativo. Pese a estos problemas, las nuevas corrientes educativas han colocado a la dimensión afectiva en un segundo plano, separando la dimensión afectiva del saber, desconociendo que los aprendizajes significativos dependen, entre otros factores, del afecto (Vanga \& Fernández, 2016).

Estos problemas, en parte son consecuencia del sistema económico de la competitividad y la sobrevivencia en el que la mayoría de las familias están inmersas. La gran preocupación de la familia es la economía. Con tal de alcanzar los logros económicos esperados, no importa el número de horas que se trabaje, aunque ello conlleve al abandono de sus hijos. Puede haber dinero para pagar colegio privado y mostrar una imagen de orgullo por ello, pero no hay tiempo suficiente para fortalecer en sus hijos otros factores, no económicos, pero indispensables para su formación integral. No hay tiempo para ayudar en las tareas, no hay tiempo para jugar con los hijos, no hay tiempo para escucharlos y darles cariño. Se llega cansado de tanto trabajar, porque el dinero es muy importante, sino quién paga los estudios, quien cubre los gustos y necesidades de la familia. Frente a esta situación el Estado ya no interviene comprometidamente, deja que la educación se rija por las reglas del mercado y el negocio. «La mediocridad y la corrupción institucionalizada en nuestros sistema educativo obstaculizan toda pretensión de cambio y de mejorar a favor de una educación integradora» (Sánchez, 2013, p. 8). 
En el mismo sentido, Díaz y Salamanca (2013), sostienen que la sociedad actual se valora más al mejor, al ganador, sin importar cómo. En este contexto surgen los perdedores y los ganadores, se acentúan el individualismo, la desigualdad, la injusticia, la violencia y un sentimiento de frustración y soledad, tanto para el que gana como para el que pierde, conllevando a actitudes negativas que penetran la cultura, los principios y valores.

\section{La universidad y los desafíos de una educación integral}

El rendimiento académico y el comportamiento son, hoy en día, grandes desafíos de la educación actual. Muchos de nuestros estudiantes muestran un desinterés, indiferencia y mediocridad frente al rendimiento y el comportamiento. El interés de algunos se reduce a obtener una nota aprobatoria. La formación y preparación profesional lo ven secundario. El comportamiento entra en el embudo del sinsentido y el mero cumplimiento. Creen vivir en un mundo sin responsabilidad. El comportamiento humano sufre una grave crisis generada por una latente incapacidad frente a las relaciones humanas y la convivencia social (Cerezo, 2014).

El desinterés por el estudio, la baja calidad de los docentes, el fracaso escolar, la precariedad de muchas instituciones educativas en la actualidad son preocupantes. La precariedad de las relaciones humanas, en los diversos contextos (escuela, familia y sociedad) reflejan cada vez una crisis más profunda del comportamiento, problemas que obligan al investigador a buscar soluciones innovadoras en beneficio de una educación integral (Pérez, Betancourt, \& Silveira, 2015).

En este contexto, muchos jóvenes se resignan a vivir en la indiferencia y la violencia. La anomía, el rechazo a las autoridades, la informalidad, el caos y el atropello de la propia dignidad son una práctica común en la vida del hombre actual. Los más débiles terminan presos de la depresión, el aislamiento y en muchos casos llegan al suicidio. La violencia generalizada y sistemática es consecuencia evidente de este fracaso (Leuridan, 2018). El éxito o el fracaso en el estudio y el comportamiento determinan la vida. El fracaso académico produce frustración, indiferencia, apatía, vulgaridad y agresividad frente a la convivencia humana (Montenegro, 2016). 
La violencia, el individualismo y el libertinaje, característicos de las nuevas generaciones son manifestaciones de la incapacidad del hombre para relaciones fraternales. La escucha y buena estima han desaparecido de la interrelación de las personas. La convivencia social es mediocre y utilitaria, se llama amigos a quienes nos sirven para nuestro propio interés, pero no para el desarrollo de una amistad sincera. La cordialidad, el respeto, la empatía y la comunicación sincera ya no son parte de las relaciones humanas. La recuperación de los valores humanos en las nuevas generaciones, mediante relaciones empáticas que crean un ambiente donde, sobre todo los jóvenes, puedan sentirse escuchados, estimados. Tales acciones despiertan sentimientos y emociones positivas, estimulan los éxitos individuales y colectivos. El afecto cambia la actitud impositiva de censura por una más cordial y afectiva (Méndez, 2014).

Y, en lo que se refiere a los aportes de la ciencia, Alarcón (2009) critica el hecho de que la investigación psicológica y psiquiátrica de varias décadas se haya centrado más en el estudio de los comportamientos negativos como los descritos en su estudio. Enfatiza que la felicidad siempre ha tenido un singular valor entre las metas de la vida, por ello se anhela, se busca y se emplea esfuerzo por alcanzarla, pero cuando esta se idealiza puede resultar lejana y esquiva.

\section{Las alternativas de solución: la educación integral}

La formación integral de la persona, misión de la educación, exige considerar una serie de elementos, que vayan más allá de la competitividad y la eficiencia, que consideren al sujeto de la educación en su integralidad. La diversidad de motivaciones que requiere el hombre para vivir permiten también su formación integral. Esta investigación se centra en el estudio de uno de esos elementos: la afectividad (pedagogía del amor), que se explicará ampliamente, demostrando paso a paso la importancia que tiene el amor y su significado en la formación integral de la persona humana. Díaz y Salamanca (2013) consideran fundamental la aplicación de la pedagogía del amor para mejorar las conductas, actitudes, empatía y compañerismo. Sostiene que a partir de ella se abrirá una puerta a la revelación de las capacidades, habilidades, destrezas, donde los estudiantes se sientan capaces de hacer $u$ opinar libremente porque saben que serán respetados, escuchados y valorados. Concluye afirmando que se trata de 
una pedagogía liberadora, formadora, socializadora, mediante la cual se puede promover una sana convivencia, comprensión, colaboración, bien común y ayuda mutua.

De Zubiría (2007) sostiene que el ambiente natural para el desarrollo del amor (afecto) es la crianza. La crianza de un hijo es una tarea cotidiana, casi instintiva. Cuidar, alimentar, vestir, asear, vigilar, son acciones de este proceso. Sin embargo, la crianza requiere de una pedagogía básica dirigida a formar, orientar y desarrollar afectivamente el amor en los hijos. Este proceso permite la adquisición de competencias afectivas intrapersonales: autoconocimiento, autovaloración y autocontrol. Interpersonales: conocer, valorar e interactuar con los demás. Tales competencias son indispensables para la convivencia adecuada en la familia, el trabajo y la sociedad.

Esta investigación, considera a la Programación Neurolingüística (PNL), una herramienta imprescindible en la pedagogía del amor y consecuentemente en la formación integral del ser humano. Esta herramienta fortalece las conductas de respuesta positiva, frente a los desafíos de la vida, cuya consecuencia es el logro de la satisfacción, la realización personal y la felicidad (Montenegro, 2016).

En consecuencia, brindaremos respuesta a las siguientes preguntas: ¿cómo influyen la pedagogía del amor y la PNL en la educación integral de la persona humana?, ¿cuáles son sus efectos en la calidad del rendimiento académico y el comportamiento?

\section{La pedagogía del amor}

Un análisis amplio de la pedagogía del amor permite ver que se trata de una actividad integradora. La planificación, ejecución y evaluación pedagógica son irreductibles a la mera consideración de procesos de enseñanzaaprendizaje de conocimientos y capacidades. La reflexión sobre los valores y buenas actitudes son indispensables en este proceso, por ser inherentes a la formación integral del ser humano. En el fondo, el objetivo de todo sistema y programa educativo integral es contribuir, no solo con el éxito académico sino con la consolidación de la convivencia familiar, laboral y social. El Ministerio de Educación del Perú (2017), mediante el Diseño Curricular Nacional (DCN), 
en el contexto de una educación integral, señala que el amor es el valor de máxima necesidad en la vida. El amor es fuente principal de convivencia. De modo más completo, Leuridan (2018) sostiene que, la buena educación se expresa en la convicción y práctica de los valores (virtudes), modo de vida que requiere del cultivo de la razón y la libertad, de la compresión de la norma, del detalle del afecto (el amor) y el buen ejemplo de los adultos.

La pedagogía del amor apunta a la acción práctica de cultivar lo más conscientemente posible vínculos afectivos que lleven al hombre a la experiencia de la felicidad. Cuando ello se logra, se obtienen los recursos vitales para sobrevivir, crecer y trascender en el amor, la sabiduría y la paz. El primer vínculo afectivo que uno debe cultivar es con la vida. La comunión con la vida y con uno mismo, es lo que le da sentido y estructura a la existencia. El amor permite pensar, sentir y actuar de forma equilibrada. De Zubiría (2007) aclara que la afectividad es el motor de la existencia, es lo que nos mueve a hacer o dejar de hacer todo. Es la clave para que nuestra vida cotidiana cobre sentido. El ser padres, hermanos, hijos, esposos, novios, enamorados, amigos, compañeros, trabajadores y emprendedores, en la perspectiva del amor cobran un gran sentido. Las emociones y sentimientos de amor, felicidad, alegría, tristeza son determinantes en la formación de actitudes, valores y principios.

La pedagogía del amor es una filosofía que busca solucionar los problemas relacionados al sano crecimiento del ser humano, su personalidad, sus capacidades intelectuales, axiológicas y sociales, cuya consecuencia directa, son los modos óptimos de convivencia humana en cualquier contexto donde nos ponga la vida. Díaz y Salamanca (2013) afirman que esta pedagogía permite identificar el origen de los conflictos y busca las soluciones acertadas. La mediación, el diálogo, la negociación son propuestas expresas del autor, para evitar el recurso a la agresión física y verbal y proteger la integridad personal y colectiva. La familia, la escuela, los amigos y el trabajo, son instituciones socioculturales mediadoras que aportan en esta tarea. Por ello, es indispensable promover la importancia de mejorar estos ambientes, sobre todo el hogar y la escuela, en todos sus niveles. La participación de padres de familia y docentes, con actitudes y detalles afectivos es crucial en la educación integral de sus hijos.

El amor es el valor que se muestra mediante actitudes de profundo respeto, valoración de uno mismo y del otro, buen trato y consideración. Según Díaz 
y Salamanca (2013), en donde el estudiante tiene autonomía e independencia. Siendo el ideal el proceso de enseñanza-aprendizaje del amor sin necesidad de imponerlo en contra de la voluntad. La pedagogía del amor promueve, es integradora sin discriminación.

Pérez et al. (2015) asiente que esta pedagogía resalta las actitudes humanas, con sentimiento de amor, profundo respeto y sentido de solidaridad con los demás y con uno mismo. Prosiguen, señalando que los efectos de esta pedagogía son la satisfacción de las necesidades afectivas, el desarrollo de la comunicación interpersonal, la consolidación de la autoestima y la empatía, de donde surgen, la motivación, la confianza, los valores y la autonomía.

Yendo a detalles más profundos, hay que considerar que «las palabras cariñosas, los besos, los abrazos, los elogios y las actitudes amables; el reconocimiento de los logros y cualidades, el aprecio y el respeto, son estrategias claves de la pedagogía del amor» (Díaz \& Salamanca, 2013, p. 23). Estas acciones son muy necesarias para la formación integral del ser humano, puesto que permiten crecer emocionalmente y construyen las bases de la confianza, la seguridad y respeto mutuo. «El amor es la acción de dominio de las conductas relacionales a través de las cuales el otro surge como legítimo» (Díaz \& Salamanca, 2013, p. 25).

El fin de la pedagogía del amor es la felicidad. La felicidad es el indicador de una mejor calidad de vida. La gratitud, el optimismo, la resiliencia, el amor, la risa, el buen humor y el bienestar son manifestaciones de la felicidad. Finalmente, la extraversión, la intensidad de experiencias emocionales, el regocijo, placer y la satisfacción son efectos de la práctica del amor (Alarcón, 2009).

La pedagogía del amor es preventiva. Es cuando una persona recibe formación afectiva tiene en sus manos poderosas herramientas para afrontar la vida. La violencia, el maltrato, son reemplazados por actitudes de cuidado e integración. Las sociedades que valoran la formación afectiva de sus ciudadanos, disminuyen significativamente sus indicadores de violencia, y por el contrario, emerge con fuerza una mejor calidad de vida, que trasciende las condiciones materiales. Todo ser humano necesita formación afectiva, sin importar la edad. Pero, si se empieza a temprana edad, mayor es el impacto. En dicho proceso, la familia, la escuela, la comunidad, los medios de 
comunicación y las organizaciones cumplen un papel fundamental. La formación de nuevas generaciones que se amen a sí mismos y a los demás, y que contribuyan a la convivencia social dependen de esta pedagogía. Aprender a ser persona, a convivir en comunidad y en sociedad, son pretensiones de la pedagogía del amor (De Zubiría, 2007).

La pedagogía del amor, según Aguilera y Martínez (2017), es un «estilo educativo que desarrolla dentro del saber ser de cada docente un hilo invisible (el amor) que une el cuerpo, la mente, la conciencia y el corazón en las acciones pedagógicas con sus estudiantes» (p. 44). Es decir, el amor es un escudo de protección y tenacidad que se logra en la conexión entre lo que se es como persona de valor y el sujeto de alteridad, mediante el dinamismo de brindar y recibir afecto. También, afirman que el amor es la gran motivación para generar una conexión entre la razón y la emoción, una reciprocidad de sentimientos y afectos, una disposición al bien del otro, y para consigo mismo, tranquilidad, creatividad y paz. Ello nos permite comprender que a pesar de nuestras distintas historias, somos capaces de sostener actitudes conscientes, más integrales, críticas y conciliadoras.

En este contexto, Olguin (2014), acota la necesidad de una educación que promueva el aprendizaje de la vida, el compartir y la comunicación. Precisa que «el cultivo del mundo emocional, del amor y las actitudes amorosas son claves para el desarrollo biológico, mental y social de las personas en desarrollo» (p. 13). «Una cultura educativa más humanizada es aquella que integra conocimientos, emociones y relaciones que enseñe a conocer, a convivir y a trabajar juntos» (p. 17). El autor señala que la universidad es un espacio clave de convivencia, donde el estudiante puede desarrollar no solo conocimientos sino actitudes para la convivencia. El estudiante se transforma según las relaciones en los espacios donde convive. En este sentido, la calidad de los procesos relacionales y emocionales que pueden darse en la familia, en la universidad y la sociedad son determinantes en la educación integral de la persona.

El amor es una de las expresiones de las relaciones sociales que juega un destacado papel en la convivencia humana. El afecto corporal y el modo de conducirse externamente, tiene una importancia especial. El trato es el canal de expresión de la persona, regla poderosa que crea convivencia con los demás. 
Ser grosero o no, saludar y dar las gracias, expresan el concepto de uno mismo y de la familia. El amor es la emoción sin la cual la convivencia no sería posible, la autovaloración y la importancia del otro se consolidan gracias al valor del amor. Querer, valorar y respetar a los demás, en una relación fraterna; expresa la comprensión de nuestras diferencias de pensamientos, sentimientos, necesidades y circunstancias (Díaz \& Salamanca, 2013).

En el fondo, la pedagogía del amor expresa lo que significa aprender a vivir como seres humanos. Olguin (2014) sostiene que lo humano no surge de la confrontación sino de la relaciones sociales entre ellos. El comportamiento humano no es efecto de la naturaleza, sino del aprendizaje. La humanidad se expresa en la confianza y paz, valores aprendidos en la interacción con quienes los poseen. El estudiante al sentirse valorado, reconocido y aceptado por los demás reafirma su autoestima, su seguridad y su calidad humana, en el caso contrario, se siente incapaz de desarrollarse como individuo (Díaz \& Salamanca, 2013).

Es decir, hay dos emociones, negativas y positivas que influyen en un clima emocional que afecta la calidad de la relación humana que potencia el aprendizaje de calidad y el desarrollo integral de la persona (Olguin, 2014).

Por lo tanto, la pedagogía del amor, señala a los demás (matrimonio, familia, amigos, etc.) como fuentes fundamentales de la felicidad. La experiencia de encuentro con los demás: padres, hermanos, compañeros, profesores, grupos, pareja, jefes, son escuelas de aprendizaje del amor. La felicidad es el resultado de quienes nos quieren y de tener a quien querer. La felicidad tiene un gran impacto en la vida, de ella depende el desarrollo interpersonal e intrapersonal del ser humano. El talento interpersonal permite la formación de vínculos sociales y el talento intrapersonal consolida la del sentido de la propia existencia. En contraposición, la amistad, el noviazgo, etc., con esa persona no tiene sentido, sería mejor concluir la relación antes que en el futuro cause mayores sacrificios. A su vez, tal valoración permitirá decidir invertir más, invertir menos, cancelar el nexo o esperar a ver cómo evoluciona la relación. La afectividad intrapersonal permite la autocomprensión y el sentido de la propia existencia. La psicología afectiva tiene como argumento a las personas felices, las que son capaces del autoconocimiento, autovaloración y autocontrol (dirigen su vida) (De Zubiría, 2007). 
Una universidad que forma a sus estudiantes mediante la pedagogía del amor debe desarrollar espacios de reflexión sobre el significado de lo humano, los valores y el sentido de la vida, para generar en el modo de pensar una nueva antropología que sirva como base para el desarrollo y fortalecimiento de la nueva cultura de la vida, de la emergencia del nuevo hombre que anhelamos.

\section{El rol de la familia en la pedagogía del amor}

La familia es el ambiente natural de la socialización primaria, el niño aprende a convivir con personas diferentes. Las acciones de compartir alimentos, participar en juegos colectivos respetando reglas, orar juntos, permiten distinguir lo que está bien de lo que está mal, seguir las pautas de la comunidad a la que se pertenece, adquirir una identidad y pertenencia (Savater, 1997).

Por tales razones, las tendencias individualistas, hedonistas y materialistas, muy presentes en la sociedad del mercado de la competencia, le quitan valor al rol de la familia en la formación humana de los ciudadanos en la perspectiva del desarrollo integral de la persona humana. Las propuestas que acusan a la familia de ser una institución nefasta y portadora de la moral del esclavo, y que por lo mismo, no convendría para formar al hombre, dejando la tarea educativa al Estado y a sus especialistas, solo forman empleados pero no personas (Leuridan, 2018).

Por el contrario, esta investigación confirma la centralidad e importancia inalienable de la familia en la formación integral de la persona, contribuyendo a su propia felicidad, a la de la familia y las buenas relaciones sociales con su comunidad. Sobre todo porque la familia trasmite valores, un conjunto de valores, sobre todo el amor a las nuevas generaciones (Pontificio Consejo para la Justicia y la Paz, 2004).

En diversas investigaciones se afirma que el actuar de los hijos está definido por los pensamientos y sentimientos aprendidos en la crianza que los padres emplearon para formarlos. Los hijos imitan el actuar de sus padres y los toman como ejemplo durante la edad temprana, sin distinguir entre lo bueno y lo malo. Los hijos solo confían en los padres. Los padres son la primera armonía, el primer orden y modelo para sus hijos. Conductas, 
gestos y movimientos, valores o antivalores son imitados por los hijos. Por ello, el trato con amor y respeto proyecta lo aprendido en las relaciones con los demás. El desarrollo afectivo de los hijos comienza con la enseñanza de los padres en su formación de hábitos, valores y actitudes con los demás (Díaz \& Salamanca, 2013; Savater, 1997).

El hogar es el lugar adecuado para el desarrollo de reconocimiento positivo o rechazo a lo negativo, para la vivencia de detalles como las caricias, miradas amorosas, gestos valorativos, etc., pero también, el lugar de los conflictos, gritos o silencios. Tales signos moldean nuestro paisaje interior y la manera de entendernos, el modo de construir una imagen del mundo y de dar un sentido a la vida.

Los seres humanos para lograr su desarrollo necesitan de la caricia externa, es decir, de actitudes, gestos y signos de reconocimiento. La caricia externa constituye, el contacto piel con piel, la mirada tierna y transparente, el gesto amable y respetuoso, el mensaje positivo; una mano de aliento en el hombro, una sonrisa amigable, una crítica constructiva, «la caricia externa es un feedback afectivo» (Steiner, 2011).

En el mismo sentido, Faulkner (1940), afirma el poder del amor o afecto para la sobrevivencia humana. La expresión, «si tuviera que elegir entre el dolor y la nada, elegiría el dolor» (p. 91), muestra, la preferencia del dolor en vez de la nada. La sensación de saberse amados, de tener algo, la conciencia de las emociones, el gozo, significan que estamos vivos. «Cuando un ser humano no sabe cómo obtener caricias positivas hace lo posible para obtener caricias negativas, antes que no tener ningún tipo de reconocimiento, de atención» (p. 75). A la falta de reconocimiento positivo surge como respuesta la provocación. Las rebeldías de los adolescentes manifiestan la búsqueda de atención del padre o madre ausente. Pégame antes que ignorarme, expresa el reconocimiento de aquella persona que ama inconscientemente. La rebeldía, los comportamientos negativos, no es más que una forma desesperada de llamar la atención. Frente a esta situación el dialogo abierto y la comunicación bidireccional son indispensables, pero sobre todo la presencia de padres ejemplares. La dinámica de grupos, equipos de trabajo, la mutua colaboración permiten el crecimiento integral. En este proceso, el insulto, la presión innecesaria, la humillación o el acoso 
son perjudiciales. Por ello, procurar que los demás estén bien ayuda a estar mejor. Actitudes como cuidar, respetar, dar alas, son esenciales. Si a un hijo, antes de comenzar un partido de futbol, se le dice te vas a caer porque eres un inútil, ese hijo se va a caer. Lo hace, porque ama, ello es el efecto primario en negativo. Pero si a ese mismo hijo se le dice, campeón, disfruta, corre, vuela, tienes alas en los pies y si te caes yo estaré por ti, ese hijo jugará mucho mejor, que lo haría si no se le dijera nada. Todo proyecto se consolida y crece, cuando se supera todo tipo de narcicismo y vanidad. El trabajo en equipo es solidario cuando todos hacen una sola fuerza, y juntos -docente y estudiantes- superan la adversidad, el reto y la crisis. La confianza mutua crea la calidad. El compromiso sin la confianza no existe. La lógica de la cooperación nace de la lógica de la confianza. Si tratamos a un ser humano como es, seguirá siendo lo que es, pero si lo tratamos como puede llegar a ser, porque confías en él, porque cooperas con él, se convertirá en lo que está llamado a ser. En este proceso los padres de familia deben considerar el amor como una gran motivación para que sus hijos, sintiéndose queridos, amados, respetados y valorados puedan superar los desafíos del rendimiento académico y el comportamiento.

Regresando a la reflexión sobre la caricia, encontramos que esta es considerada un elemento clave dentro de la educación emocional. Esta teoría de Steiner (2011) afirma que «amar a uno mismo y a los demás y ser amado por uno mismo y por los demás es esencial». Una persona se vuelve más cariñosa, cuando siente amor por los demás. «La falta de caricias pueden provocar un retraso en el desarrollo psicológico y una degeneración física tal que puede llevar a la muerte» (p. 26). La ternura, el cuidado, el afecto y la atención permiten el desarrollo psicológico, emocional, intelectual y físico de la persona. «El hombre se hace más humano gracias a la caricia, al estímulo amable, a la ternura, a la compasión y la gratitud. La presencia o ausencia de la caricia tiene efectos indescriptibles sobre el ser humano y su crecimiento integral» (Faulkner, 1940). El amor de los padres es un soporte moral importante que los hijos utilizan frente a los retos de sus proyectos personales, sobre todo los retos del estudio.

En consecuencia, la vocación de los padres de familia se refleja en la compresión de su responsabilidad con la formación integral de sus hijos. Es importante que los padres de familia se preocupen por el sustento y 
condiciones materiales que sus hijos demandan, pero más importante es, además de ser cooperadores con Dios en la trasmisión de la vida, contribuir en la consolidación de amor en las relaciones con sus hijos. Con el amor, los padres de familia contribuyen a la formación integral de sus hijos, a mejorar la calidad del rendimiento académico y optimizar su comportamiento.

\section{El rol del docente en la pedagogía del amor}

La educación no es meramente un asunto de adiestrar mentes, no es una simple adquisición de conocimientos, tampoco es una correlación de datos. La educación es un proceso de formación integral, que engloba el desarrollo cognitivo, afectivo y social de la persona, que se inicia en la familia, se continúa en la escuela y se consolida en la sociedad. Argyle (1992) sostiene que el valor de educar no se reduce a la formación del intelecto sino que trasciende prioritariamente a la formación de la afectividad permitiendo formar personas felices tanto física y mentalmente (Argyle, 1992).

Ante el avance vertiginoso de la ciencia y la tecnología, cada vez más inmersos en los ambientes educativos y la vida cotidiana, la pedagogía del amor significa la recuperación de los valores tales como el respeto a la persona humana y su dignidad, la cooperación y solidaridad con los semejantes. En este proceso, Pérez et al. (2015), determina que la tarea de una educación integral es formar hombres íntegros, inteligentes, capaces de descubrir valores permanentes, innovar las relaciones humanas y sociales, y despertar en las nuevas generaciones actitudes de compresión mutua y autocompresión. La formación integral de la persona, implica no solo el desarrollo de conocimientos, habilidades, normas, sino sobre todo la reflexión y práctica de los valores éticos y morales, cuya consecuencia es la inserción del hombre en su comunidad y la cultura de su pueblo o nación, además de permitirle el logro de su realización personal, de sus metas y fines, sobre todo, la felicidad. El desarrollo del conocimiento, como condición del alto rendimiento, es esencial no solo para el desarrollo de capacidades cognitivas, sino sobre todo, para el buen vivir. En este sentido, la educación constituye uno de los principios esenciales para justificar nuestras ideas, principios y valores, y aprender a discernir lo que nos conviene y lo que no, y el bien común. Un enfoque pedagógico no solo 
cognitivo, sino también humanista y afectivo, que respete las propias raíces culturales ayuda grandemente a la educación a lograr sus objetivos.

Pérez et al. (2015) ven en la pedagogía del amor una herramienta efectiva en la búsqueda de soluciones a los diversos problemas educativos. Permite al estudiante ser congruente con las relaciones educativas, mostrarse tal cual es, expresar sus sentimientos y pensamientos. Por ello, se sugiere al docente tener confianza en la posibilidad de cambio de sus estudiantes, ser empáticos y saber escucharlos. El trato afectivo de las dificultades de los estudiantes, genera inclusión y aceptación de los demás, con quienes se comparte el espacio y el tiempo. La pedagogía del amor vincula la dimensión cognitiva con la dimensión afectiva, buscando un mayor dinamismo en las tareas inherentes al proceso de enseñanza-aprendizaje. Por ello, este modelo pedagógico es problematizador, desarrollador y dinamizador; es reflexivo, sistémico, valorativo y auténtico. Es la realización de un proceso dialéctico de apropiación de la propia cultura, donde el afecto crece naturalmente, dando lugar al surgimiento de un sistema educativo fundado en sus propias raíces culturales.

Por su parte, Gardner $(2000,2001)$ hace notar que la existencia de la dimensión de la vida personal es de gran importancia para la formación del hombre. La pedagogía del amor emerge en este contexto como un conjunto de motivaciones afectivas que permiten al hombre trabajar con esmero y perseverar en sus emprendimientos. Tal es la importancia del afecto para el autor que su nueva psicopedagogía destierra la falsa hegemonía de la inteligencia verbal-académica del coeficiente intelectual (CI) y abre camino al desarrollo de aptitudes intrapersonales e interpersonales, denominadas competencias afectivas.

La educación integral conecta el desarrollo del conocimiento con el desarrollo de valores afectivos: respeto mutuo, relaciones pacíficas y colaborativas. Tal perspectiva, contribuye a la formación de personas felices, autónomas, responsables y solidarias. Olguin (2014) afirma que la educación integral, exige la presencia de docentes ricos no solo en conocimiento de contenidos curriculares, sino también que gocen de habilidades y estrategias que permitan la gestión del trabajo colaborativo, la vida afectiva y relacional del grupo clase, en miras a la convivencia. 
Piaget (1999) en su obra Criterio moral del niño, aborda la dimensión afectiva, poniendo, de ese modo, las bases del estudio de los valores y la formación del juicio moral. La pedagogía del amor destaca la importancia de la dimensión afectiva de la persona humana, por ser una condición fundamental y vital inherente al proceso educativo. Considera el afecto para la construcción de la personalidad su proceso evolutivo y la convivencia social, por ello, el afecto, es hoy en día, un tema preocupante en los ámbitos familiar, escolar y social.

Por consiguiente, la pedagogía del amor permite enfrentar a diario problemas familiares, sentimentales, económicos y sociales (Méndez, 2014).

Se recomienda a los docentes integrar a todos los estudiantes para fortalecer lazos entre ellos, que permita mejorar las relaciones en el salón de clases, lo que influirá en el proceso de aprendizaje (Díaz \& Salamanca, 2013).

En el mismo sentido, Solano (2015) considera que la pedagogía del amor es el camino para el desarrollo de diversas capacidades humanas, tales como, la sensibilidad individual y la participación responsable en la sociedad, la originalidad personal y la creatividad, la adaptación al cambio y el desarrollo de valores éticos, la primacía de la vida humana individual y colectiva, y la preservación de la naturaleza y el medio ambiente. Acota que la valoración de la dignidad humana, la justicia, la libertad y la solidaridad se aprenden en la familia y se refuerzan en la escuela.

Olguin (2014) advierte que de no darse las suficientes interacciones afectivas, en la familia y la escuela se obstaculiza el desarrollo de la persona tanto en lo concerniente a los aprendizajes, la salud y la socialización. Sentirse útil, valorado, amado y aceptado, sobre todo por las personas significativas de nuestra vida, garantiza el desarrollo humano integral de la persona.

Asimismo, el Proyecto Aldea Educa (2013) sostiene que el amor y las actitudes afectivas son importantes para el desarrollo personal. El afecto es una emoción trascendental que ayuda al desarrollo interpersonal e intrapersonal. Acciones como la comunicación, la autoestima son necesarias para el crecimiento integral de la persona. 
Los estudiantes aprenden en los espacios donde conviven, sobre todo en la familia y la escuela. Es por eso que las instituciones educativas deben desarrollar lugares adecuados para la comunidad educativa. La intolerancia en la práctica docente lesiona la autoestima y conlleva a la pérdida de credibilidad. Por ello, proponer normas democráticas es indispensable no solo para la convivencia humana sino también para crear autonomía en el estudiante. De este modo la escuela se convierte en comunidad de personas donde el respeto mutuo construye una sociedad armoniosa. La ternura y el afecto son claves para el desarrollo de relaciones pacíficas. En este proceso actitudes como el manoseo, el permisivismo no se identifican con el verdadero afecto. La pedagogía del afecto articula empatía y firmeza, el docente puede ponerse en la situación del niño, acercarse a él, pero también debe mantener su autoridad suficiente, estableciendo límites necesarios para una armoniosa convivencia (Proyecto Aldea Educa, 2013).

Se considera al afecto como un elemento clave que ayuda a modificar el cerebro de las personas. "Un estudiante expuesto a relaciones y demostraciones de afecto, no solo se desarrolla distinto a uno carente de afecto, sino que su cerebro cambia y, por tanto, se modifican sustancialmente sus posibilidades y capacidades como persona» (Saavedra (2010, p. 3). El afecto es un factor decisivo en la relación maestro-alumnos, en el logro académico por encima de las calificaciones. Los profesores que consiguen mejores relaciones con sus alumnos alcanzan mejores resultados, logran desarrollar empatía y simpatía, comprensión y cariño, expectativas y autoestima, confianza en sí mismos.

El amor es un elemento sustancial para lograr una educación de calidad, es decir, la calidez es inherente e inseparable de la calidad, cuando se trata de formación del ser humano. Por ello, se advierte que cuando un estudiante, por sus deficiencias académicas, es estereotipado como bruto, en vez de ayudarlo a mejorar se le está abandonando a su suerte, condenando y culpabilizando de su fracaso. La desaprobación de los cursos, el abandono de la carrera pueden ser consecuencias de la falta de afecto en las relaciones docente-estudiante. Esa nefasta experiencia marca de por vida al estudiante y lo predispone al fracaso. Actitudes atentas y de afecto por parte de los docentes y compañeros, pueden evitar el fracaso del estudiante. Actitudes despectivas por parte del docente solo refuerzan la 
imagen de incapaz del estudiante y solo contribuyen a su fracaso. Es así que identificar y resaltar más los talentos que sus debilidades recupera la confianza del estudiante en sí mismo y lo predispone al éxito (Torres, 2011).

El docente es el entorno de los estudiantes: nadie puede ser alguien sin un entorno 'amoroso' que le haga posible ser. Por lo tanto, las tareas de diagnóstico del nivel motivacional de los estudiantes, el nivel de conocimientos, el nivel de compresión, sus preferencias relacionales son indispensables en el trabajo docente. Debe crear un ambiente favorable y evitar actitudes agresivas: presentar 'cara de pocos amigos' provoca en el estudiante la misma postura, ayudan a superar los sentimientos de discordia y promueven la conciliación, la tolerancia y la cooperación. El amor promueve concordancias y el resentimiento discrepancias. Sintonizar con los intereses de los alumnos, escuchar sus puntos de vista y sus opiniones, compartir sus experiencias, crea conductas relacionales y convivencia en el grupo (Proyecto Aldea Educa, 2013).

Mena (2013) por su parte, advierte que los factores motivacionales afectivos actúan como retroalimentación positiva. El amor, el respeto, la consideración, la valoración, la escucha atenta, crean seguridad en el estudiante para enfrentarse naturalmente a los retos del estudio. En la misma perspectiva, Bloom (1997) sostiene que existe una interacción entre el afecto y el éxito en el alto rendimiento: el afecto estimula positivamente el rendimiento académico y el logro de este estimula un impulso a la afectividad. Es la misma línea, Savater (1997) sostiene que la enseñanza debe incentivar la autoestima de los alumnos.

Finalmente, Goleman (1996) sostiene que la inteligencia interpersonal y la inteligencia intrapersonal sirve para comprender a los demás y a uno mismo. Reivindicar los sentimientos y afectos humanos es importante, ellos nos dicen algo sobre nosotros mismos y del mundo en que vivimos, son canales de percepción de lo interesante, lo que nos afecta. «La educación de los sentimientos, la educación sentimental, no es cuestión para telenovelas, sino el núcleo de una educación humana, humanista, orientada no solo a formar futuros trabajadores, sino mejores seres humanos» (Marina, 1996, p. 5). Sin los sentimientos los conocimientos no podrán discernir lo interesante, lo que afecta, el sentido de la vida, poniendo al hombre en la mera condición de autómata laboral. 


\section{Programación neurolingüística (PNL) y formación integral de la persona}

El antecedente de la PNL está en la teoría de Alfred Korzybski (1933): «El mapa no es el territorio», explicada en su obra Science and Sanity. Conceptos como «aprendizaje neurolingüístico», «reacciones neurolingüísticas» $\mathrm{O}$ «efectos neurolingüísticos» ya están en la obra de este autor.

Un mapa no es el territorio que representa, pero, tiene una estructura similar al territorio, razón por la cual resulta útil. Una palabra no es el objeto que representa, los lenguajes también exhiben esta peculiar capacidad de reflejarse a sí mismos. Si reflexionamos acerca de nuestros lenguajes, encontramos que, en el mejor de los casos, deben ser considerados tan solo como mapas. (Korzybski, 1933, p. 26)

El lenguaje de mapas es un desastre semántico. Impone y refleja su estructura antinatural, considerando que las palabras y los objetos representan dos cosas distintas. Una es la estructura de los procesos verbales y otra los datos empíricos. Las palabras no son las cosas de las que hablamos, entonces, el único vínculo posible entre el mundo objetivo y el mundo lingüístico se halla en la estructura. La utilidad del mapa o lenguaje depende de la similitud entre el mundo empírico y los mapaslenguajes. Porque el lenguaje es estructura, el hombre inconscientemente lee el mundo de la estructura, el lenguaje que usamos. (Korzybski, 1933, p. 55)

La naturaleza neurolingüística de todo ser humano permite procesar la información. Los seres humanos tenemos un estilo de vida semántico. El hombre es un ser semántico, y los seres semánticos se comunican mediante símbolos, es por ello que sus respuestas a los estímulos externos se realizan por medio de mapas y no de realidad. Vivimos usando un sistema de símbolos (mapa) distintos de la realidad (el territorio). La semántica afecta directamente al sistema nervioso. El cerebro piensa y expresa el lenguaje en palabras y formas. Los sentidos, que conforman el sistema sensorial (cortex visual, cortex auditivo y corte kinestésico), mediante nuestro sistema nervioso, perciben el estímulo (información), lo procesan y crea representaciones abstractas, internas (mapas). Cuerpo y mente funcionan unidos. El éxito de los humanos se 
sustenta en el uso estratégico de símbolos y la habilidad de una comunicación clara y exacta. Todos construimos un mundo basado en el significado de las palabras y frases, en símbolos. Lo que decimos no es esa cosa, sino solo lo expresa, sin embargo, el sistema de símbolos es el único camino que nos conecta con los demás. Las soluciones a nuestros problemas, se encuentran en el nivel verbal, es por eso que la PNL recoge el sistema de símbolos como elemento fundamental en los procesos de la comunicación humana, sobre todo en los procesos de enseñanza-aprendizaje (Korzybski, 1933).

Bandler y Grinder (2004) retomando la teoría de «el mapa no es un territorio», nos explican lo que sucede con la aplicación de la PNL. Sostienen que el proceso de la comunicación dirige al cerebro al logro de resultados óptimos en el aprendizaje y el comportamiento. Richard Bandler (estudiante de lingüística) y John Grinder (estudiante de informática y matemáticas), trabajaron juntos buscando mejores resultados en sus pacientes, en la recuperación de sus enfermedades.

Esta herramienta centra su atención en la estructura de la experiencia de cada quien, más que en el contenido de ella. El mundo subjetivo de la experiencia es comunicado a los otros mediante el lenguaje. La conducta es resultado de complejos procesamientos neurofisiológicos de la información, percibida por nuestros cinco sentidos. El modelo de comunicación holística de la PNL con sus reglas o pautas lleva al logro de objetivos trazados (Montenegro, 2016).

En esta perspectiva, Amaya y Martínez (2011) hacen notar que el comportamiento de los padres de familia, del docente y del estudiante determina el éxito o fracaso en el proceso de la formación humana. Cuando el padre de familia o el docente tienen actitudes resistentes al cambio, el rendimiento académico y el comportamiento del estudiante, se reduce o limita a responder indicaciones. El limitado empoderamiento y participación de los estudiantes en los procesos de enseñanza-aprendizaje, el diálogo y la escucha, limita también la interacción afectiva. «La tendencia a una educación que se centra en la reproducción de conceptos y pensamiento lógico, en lugar de la reflexión, el análisis, la crítica y la creación», obstaculiza el proceso de formación integral (Amaya \& Martínez, 2011, p. 7). 
El comportamiento de los estudiantes carente de valores y habilidades sociales obstaculiza la integración, el trabajo en equipo, el planteamiento de metas y objetivos. Detalles como «la impuntualidad, la inasistencia, la falta de interés en el cumplimiento de tareas, la escasa participación en clases son serios limitantes de una formación integral» (Amaya \& Martínez, 2011, p. 9).

El comportamiento de los agentes educativos (padres, docentes y estudiantes) requiere de constantes innovaciones cada vez más acordes con las exigencias de la educación integral. En la actualidad, la PNL es una herramienta, una estrategia de la asertividad de la conducta, nos presenta un conjunto de actitudes, gestos, detalles, estrategias, métodos para mejorar la capacidad de respuesta de los estudiantes a las exigencias de una educación integral. Dentro de esos detalles, la dirección afectiva de la clase y la disciplina flexible, firme, suave, activa, acogedora, que inspire confianza y respeto. El ambiente propicio incita a la asistencia y participación activa de los alumnos. «El aula de clases debe ser considerada un espacio de oportunidades para el desarrollo y no lugar neutro donde el único interés sean los conocimientos y el intelecto» (Amaya \& Martínez, 2011, p. 66). El aula debe ser el lugar, ciertamente del desarrollo de conocimientos, pero sobre todo, el espacio, donde se dan las relaciones afectivas, los vínculos y las alianzas, la buena comunicación, y el logro de resultados óptimos en el rendimiento y el comportamiento. Escuchar con empatía y sin criticar son detalles fundamentales a considerar por el maestro (Bandler \& Grinder, 2004).

La PNL es, sobre todo, una estrategia y modelo de comunicación interpersonal. De la calidad de comunicación interpersonal dependen la comprensión, el buen funcionamiento de mente, la correcta percepción humana, la acertada manera de procesar la información y las experiencias, y por ende, la formación integral de la persona.

Por tal motivo, O’Connor y Seymour (1992) definen a la PNL como el arte y la ciencia de la excelencia personal y profesional, capaz de proporcionar a las personas y a las organizaciones, herramientas de comunicación que permiten obtener mejores resultados. Afirman que tal disciplina describe la dinámica fundamental entre la mente (neuro) y el lenguaje (lingüístico), y cómo la relación entre ambos afecta al cuerpo y al comportamiento humano (programación). El término lingüística se refiere a los medios de comunicación 
humana (verbal o no verbal): cómo nos interrelacionamos y comunicamos con los demás, y programación se refiere a la aptitud para producir y aplicar programas de comportamiento. Por último, neuro se refiere a las percepciones sensoriales que determinan nuestro estado emocional subjetivo.

Sin embargo, cabe precisar que «esta herramienta no se limita a ser una técnica para optimizar la comunicación y el aprendizaje. Se constituye en el método para el desarrollo de las capacidades, la excelencia, la sabiduría y una visión más amplia del mundo» (Vanga \& Fernández, 2015, p. 33).

Para Sambrano (1997) es una «herramienta para desarrollar un pensamiento estratégico y sistemático para el logro eficiente de las metas propuestas» (p. 41). En esta perspectiva se entienden todos los esfuerzos de la ciencia por brindarnos una mejor calidad de vida. En el sentido de alcanzar las metas propuestas, ayuda a lograr cambios personales, y la adquisición de conductas más humanas.

Vanga y Fernández (2015) observan en la PNL una posibilidad de ser aplicada en otros aspectos de la vida más allá de los procesos de enseñanza-aprendizaje. Sostienen que su aplicación sirve también para eliminar o controlar la ansiedad, el estrés, los miedos, adicciones, fobias, depresiones. Esta tecnica ayuda a nivel emocional a las personas a enfrentar la vida personal, laboral, familiar y académica. En el mundo de la educación incide directamente en la mejora de resultados académicos. Ayuda a perfeccionar el comportamiento, las buenas relaciones y la formación de diversas habilidades sociales.

Precisan, Vanga y Fernández (2015), que el docente sepa que la PNL es también una poderosa herramienta de comunicación, influencia y persuasión: con sus estrategias se puede dirigir el cerebro hacia el logro de resultados óptimos. Promover una actitud optimista conduce a las experiencias de éxito y logro de objetivos. Aplicar técnicas motivacionales lleva a actuar con más ganas frente a los retos. Promover la comunicación asertiva, mejorar la confianza personal y el desarrollo de la creatividad, así como, el cambio de actitudes negativas a positivas, lo que ayuda a vivir mejor y mejorar la salud.

En la misma perspectiva complementan Amaya y Martínez (2011), quienes observan en la PNL un conjunto de actitudes, herramientas, percepciones y 
aprendizajes capaces de cambiar la forma de pensar y actuar (cada vez más positivos) de los agentes educativos: docentes, padres de familia, líderes sociales y estudiantes. Por consiguiente, proponen estos detalles: hablar siempre desde un punto de vista positivo, usar siempre un lenguaje apropiado y respetuoso, pensar en las consecuencias de nuestras acciones, hacer sentir dignos y capaces de sus avances a los demás, evitar críticas a los errores y siempre buscar soluciones a los problemas, tratar a cada uno como únicos, evitar las comparaciones de la actitudes o comportamientos y tener siempre actitudes de reconocimiento. Que las expresiones de satisfacción y de ánimo acompañen la culminación de las tareas.

Cortez y Narciza (2015), complementan, afirmando que tales detalles tienen el poder de lograr cambios significativos: «elevar la autoconfianza y la autoestima», "potenciar las capacidades comunicativas, las relaciones interpersonales y sociales de los estudiantes» (p. 36). De ello depende también el logro de capacidades para el aprendizaje autónomo, creativo e integral. Además, se sugiere al docente aplicar la estrategia de las cuatro $p$ en el aula: paciencia, ponderación, pronunciación y prudencia. «El éxito en el rendimiento, en un 38\% depende del tono de voz (palabra), en un 55\% del uso de la inteligencia de lenguaje corporal (gesto), en los procesos de la comunicación. La palabra bien dicha tiene resultados de excelencia» (p. 40).

El estudio de la PNL nos permite conocer la dimensión holística del aprendizaje. Unos aprenden mejor viendo, otros escuchando y otros palpando el objeto de estudio.

El aprendizaje visual, invita al docente a aprovechar, las fortalezas visuales de los estudiantes. Según Bloudani (2015) las personas que aprenden mediante la vista son organizadas, ordenadas, observadoras y tranquilas, ello les permite evitar las faltas ortográficas, pues visualizan las palabras antes de escribirlas. Señala que estas personas se distraen cuando hay movimiento de desorden visual; el ruido, por el contrario, no les molesta. Acota que quien goza de una inteligencia visual, recuerda con más facilidad lo que ven, piensan con imágenes y de ese modo absorben grandes cantidades de información con rapidez. «La visualización permite relacionar distintas ideas y conceptos, permitiendo una mayor capacidad de abstracción» y aprendizaje (Bloudani, 2015, p. 10). Los gráficos, cuadros, láminas, vídeos, películas, etc., ayudan mucho a estas personas en el logro de sus aprendizajes. Se sugiere una postura 
rígida, movimientos hacia arriba, respiración superficial y rápida, voz aguda, ritmo rápido, entrecortado y palabras visuales (ver, mirar, observar).

Sambrano (1997) propone como estrategia para un aprendizaje efectivo, tener en cuenta los detalles descritos en la Tabla 1.

Tabla 1

Estrategias visuales para optimizar el aprendizaje

\begin{tabular}{cc}
\hline & Estrategias para un aprendizaje efectivo \\
\hline Indicadores & Estrategias visuales \\
\hline
\end{tabular}

1. Mirar los objetos que nos rodean.

2. Distinguir las sombras de los relieves.

3. Cerrar los ojos y tratar de recordar los objetos observados, con el mayor número de detalles.

4. Cerrar los ojos e imaginar las cosas.

5. Hacer anclajes visuales.

6. Ver la TV quitándole el sonido.
1. Observar sus formas, volúmenes, tamaño, color.

2. Observar el alto, ancho de los objetos.

3. Colores, matices, formas y tamaños.

4. Imaginarse uno mismo en alguna situación de la vida cotidiana.

5. Ver un objeto determinado y asociarlo con los que uno va aprendiendo. Recordar cómo es una habitación, una calle, una ciudad de forma asociada, viéndolo con los propios ojos.

6. Prestar atención a las imágenes, cerrar los ojos y repetir las imágenes mentalmente, y entender el argumento observando la mímica.

Nota: Adaptado de Sambrano (1997, pp. 13-15).

Amaya y Martínez (2011) explican el significado de la visualización y sus efectos en los logros del aprendizaje descritos en la Tabla 2.

Con respecto a los que aprenden mejor escuchando, Bloudani (2015) lo denomina aprendizaje auditivo. Las personas que tienen inteligencia auditiva, acota, desarrollan un proceso de pensamiento ordenado y secuencial. Ello se manifiesta en detalles como: hablar solos, distraerse fácilmente y mover los labios 
al leer. Estas personas aprenden lo que oyen, el ruido es perjudicial para ellos. Los audios, los debates y las lecturas en voz alta mejoran sus aprendizajes.

Esta forma de aprender oyendo, implica una postura distendida, una posición de escucha telefónica, respiración amplia, voz bien timbrada, ritmo mediano y palabras auditivas (oye, escucha).

\section{Tabla 2}

Tabla sobre el significado de la visualización y sus efectos en el aprendizaje.

La visualización y sus efectos en el aprendizaje

Estrategias visuales Significados y efectos

1. La mirada directa expresa:

2. Sostener la mirada demasiado tiempo, expresa:

3. La mirada esquiva señala:

4. La mirada social, (formando un triángulo entre los ojos y la boca) establece:

5. La mirada dirigida al centro de la frente del interlocutor indica:

6. Mirar de reojo, acompañado de la revelación de las cejas y/o sonrisa, significa:

7. Pero, acompañado de fruncir el ceño y/o moverse las comisuras de la boca hacia abajo, significa:
1. Real deseo de comunicarse abiertamente.

2. Desafío o demasiada atracción por el interlocutor. Dicha forma de mirar, puede generar incomodidad.

3. Falta de sinceridad o deseos de ocultar algo.

4. Una cordial relación con el otro.

5. Seriedad y capacidad de negociación.

6. Interés en el otro.

7. Hostilidad o sospecha.

Nota: Adaptado de Amaya y Martínez (2011, pp. 9-11).

Sambrano (1997) propone algunos detalles para el desarrollo del aprendizaje auditivo (Tabla 3).

Jarife y Pomares (2011) sugieren a los docentes escuchar empáticamente. La actitud básica de la escucha empática consiste en escuchar de forma activa. 
Tabla 3

Estrategias para el aprendizaje auditivo

\begin{tabular}{cc}
\hline & El aprendizaje auditivo \\
\hline Indicadores & Estrategias auditivas \\
\hline
\end{tabular}

1. Hacer una excursión al campo.

1.1 Sentarse y cerrar los ojos.

1.2 Percibir todos los sonidos que lleguen.

2. Poner nombre a los sonidos.

2. Hacer una lista de ellos mentalmente.

3. Haz una lista con nombres, adjetivos y verbos relacionados con la audición.

3. Aclamar, carcajada, entonación, melodía, risotada, estrepitoso, charlar, predicar.

4. Escucha de la TV o la radio.

4. Cerrar los ojos e identificar el estado de ánimo de alguna persona por medio del sonido de su voz.

5. Fijarse en los sonidos que emiten las personas.

5. Palabras, tonos, ritmos, registros y timbres de voz, y repetirlos mentalmente.

6. Poner una canción de algún grupo musical.

6.1. Identificar los distintos instrumentos.

6.2. Formar una orquesta imaginaria en la cabeza. Oír cada uno de los instrumentos.

Nota: Adaptado de Sambrano (1997, pp. 15-16).

Completando la teoría de los canales del aprendizaje, Bloudani (2015) explica el aprendizaje kinestésico, afirma que «algunos aprenden a través de la elaboración de su propio material al interactuar con él». Para ello asocian los contenidos a los movimientos o sensaciones corporales. Se advierte que para estas personas, la clase meramente expositiva es una tortura. Balance en la silla, levantarse de la clase, hacer dibujos o garabatos expresan su rechazo. Les gusta tocar todo, se mueven y gesticulan mucho. Estas personas pueden ser descubiertas, cuando manifiestan que les gustan las historias de acción, cuando se mueve al leer, y cuando presentan faltas de ortografía. Estos estudiantes, recuerdan lo que hacen pero no los detalles, su aprendizaje es más lento y trabajan mejor en tareas de tiempo limitado y con varios descansos.

Según Sambrano (1997), estos estudiantes mejoran su aprendizaje mediante los experimentos, dibujo y pintura, actividades físicas y juegos de rol. Las explicaciones visuales o auditivas los distraen y excluyen rápidamente. Recuerdan más lo que hacen, que lo que ven o escuchan, principalmente 
prefieren el deporte y el arte. El aprendizaje kinestésico implica una postura muy distendida, movimientos que miman las palabras, respiración profunda y amplia, voz grave, ritmo lento con muchas pausas y referencia a las sensaciones en la elección de palabras (siente, atiende, huele, saborea).

Amaya y Martínez (2011) explican el significado de los detalles de la inteligencia kinestésica en la Tabla 4.

En la metodología del estudio, el recurso a los anclajes es fundamental. El anclaje se refiere a la asociación automática entre un estímulo y una respuesta emocional. En anclajes se fundamenta la publicidad, por ejemplo, cuando la publicidad de un producto hace tener hambre. El anclaje permite emocionarse cada vez que se escucha el cóndor pasa (me viene a la cabeza mis caminatas en las alturas de los Andes). Podemos crear anclajes a la carta, analógicos o digitales, encadenados o apilados, fisiológicos o cognitivos. Podemos colapsar anclajes o hacer autoanclajes (Yepes, 2016).

La fuerza del anclaje marca nuestra vida y determinan nuestras sensaciones y conductas. Percibir un olor extraño obliga al cerebro a buscar en su interior qué es ese olor. En milésimas de segundos relaciona con el mismo olor que percibió cuando tenía cinco años (sensación muy desagradable de soledad, de abandono y de miedo). Han pasado muchos años desde entonces y yo no había vuelto a oler aquel olor, pero en mi cerebro se había quedado 'anclada' la asociación entre aquel olor y la respuesta emocional. Esa es la lógica para entender el aprendizaje significativo: el recurso a los conocimientos previos de Ausubel (Palmero, 2010; Rodríguez, 2010).

Desde esta perspectiva se puede entender también la ansiedad, extraordinaria herramienta que tiene el ser humano, que se activa en el momento en que nuestro cerebro considera que existe un peligro real contra la vida. Ante una situación de peligro real, e incluso cuando ya ha pasado el peligro, nuestro cerebro envía ansiedad (Yepes, 2016). 


\section{Tabla 4}

Estrategias kinestésicas para optimizar el aprendizaje

\begin{tabular}{|c|c|c|}
\hline & Estrategias kinestésicas & Significado \\
\hline & Ladear la cabeza. & $\begin{array}{l}\text { 1. Es signo de coquetería, timidez y especialmente de } \\
\text { atención. }\end{array}$ \\
\hline 2. & La cabeza hacia arriba. & 2. Actitud neutral frente a lo que se dice 0 acontece. \\
\hline 3. & $\begin{array}{l}\text { La cabeza exageradamente hacia arriba y } \\
\text { mirada hacia abajo. }\end{array}$ & 3. Un índice de soberbia. \\
\hline & La cabeza hacia abajo. & $\begin{array}{l}\text { 4.1. Actitud negativa. } \\
\text { 4.2. Desaprobación respecto de lo que el otro dice. }\end{array}$ \\
\hline 5. & $\begin{array}{l}\text { Las manos detrás de la cabeza, enlazadas } \\
\text { forman un triángulo. }\end{array}$ & $\begin{array}{l}\text { 5.1. Gran confianza en sí mismo. } \\
\text { 5.2. Sentimiento de superioridad y dominio. }\end{array}$ \\
\hline & Las palmas hacia arriba. & $\begin{array}{l}\text { 6. Sinceridad: quien lo realiza no tiene nada que } \\
\text { ocultar. }\end{array}$ \\
\hline & Frotarse las manos. & $\begin{array}{l}\text { 7. Actitud positiva: felicidad frente a los buenos } \\
\text { resultados. }\end{array}$ \\
\hline & $\begin{array}{l}\text { Entrelazar las manos frente al rostro, apoyando } \\
\text { los codos sobre la mesa. }\end{array}$ & 8. Actitud hostil. \\
\hline & Tomarse las manos por detrás de la espalda. & $\begin{array}{l}\text { 9. Actitudes de autoridad: el policía, el director del } \\
\text { colegio, el militar. }\end{array}$ \\
\hline & $\begin{array}{l}\text { Tomarse las manos por detrás de la espalda, } \\
\text { tomando una de las muñecas. }\end{array}$ & 10. Frustración e intento de autocontrol. \\
\hline & Mostrar el pulgar manifiesta. & 11. Superioridad, falta de humildad. \\
\hline & $\begin{array}{l}\text { Sacando el pulgar de los bolsillos o brazos } \\
\text { cruzados. }\end{array}$ & 12. Agresividad y dominio. \\
\hline & Cruzarse de brazos. & 13. Actitud defensiva. \\
\hline & $\begin{array}{l}\text { Cruzar un brazo sobre otro viéndose ambas } \\
\text { manos, tomando los brazos. }\end{array}$ & 14. Nerviosismo y refuerza la actitud defensiva. \\
\hline & Las manos en la cintura o caderas. & $\begin{array}{l}\text { 15.1. Estar preparados para entrar en acción. } \\
\text { 15.2. Actitud de alerta, agresividad, seducción. } \\
\text { 15.3. Lucir una prenda y mostrar su atractivo }\end{array}$ \\
\hline & Taparse la boca o tocarse la nariz. & 16. Mentira, deshonestidad, ocultando algo. \\
\hline & Frotarse los ojos o las orejas. & $\begin{array}{l}\text { 17.1. No se está diciendo toda la verdad. } \\
\text { 17.2. Cuando la mentira es grande se desvía la vista y la } \\
\text { mirada hacia abajo. }\end{array}$ \\
\hline & $\begin{array}{l}\text { Frotarse un ojo o una oreja, rascarse el cuello, tirar } \\
\text { del cuello de la ropa o llevarse los dedos a la boca. }\end{array}$ & 18. Inseguridad. \\
\hline 19. & Repasar el mentón con una mano. & 19. Toma de decisiones. \\
\hline 20. & Posar la mano abierta sobre la mejilla. & 20. Aburrimiento. \\
\hline 21. & La mano cerrada. & 21. Evaluación de una situación. \\
\hline
\end{tabular}

Nota: Adaptado de Amaya y Martínez (2011, pp. 12-13). 


\section{La calidad del rendimiento académico y del comportamiento, indicadores de una educación integral}

\section{El rendimiento académico de excelencia}

Los cambios sociales, económicos y culturales, de las últimas décadas, han modificado la estructura familiar, la conducta y las relaciones, con consecuencias determinantes para el rendimiento académico. Las bajas calificaciones y la carencia de valores como el respeto, la responsabilidad, la dedicación al estudio, etc. reflejan tal situación.

Solano (2015) define la calidad del rendimiento académico como el éxito del aprendizaje, el alto nivel de conocimientos, está motivado por un conjunto de factores personales (capacidades cognitivas y actitudes valorativas), socioculturales (el docente y la metodología) y psicológicos (inteligencia, personalidad, motivación). El aprendizaje es un proceso socioconstructivo: social, cultural e interpersonal, mediante el cual el estudiante aprende, recibe, selecciona y almacena información, luego la codifica, analiza e interpreta para construir sus conocimientos. La evaluación nos da indicadores y resultados del rendimiento académico, con relación a las áreas, las asignaturas y los objetivos de aprendizaje. La inteligencia, el razonamiento verbal y abstracto, la memoria y la percepción son las aptitudes mentales influyentes en el rendimiento académico.

Tomando en cuenta la advertencia de Piaget (1999), quien considera a las alteraciones de la percepción visual, auditiva y táctil como limitantes del aprendizaje y el rendimiento, es necesario tener una visión más amplia de los factores que intervienen en su proceso.

La calidad del rendimiento académico requiere de escuelas altamente calificadas, familias sólidas, en los planos social, económico, moral y cultural. La familia, la economía, la salud y la nutrición son factores externos determinantes en el rendimiento académico; la calidad de los contenidos, métodos, profesores, materiales de estudio, gestión educativa y sistema de evaluación, son factores internos (Solano, 2015). 
Sánchez (2013), en la misma perspectiva de integralidad, sostiene que la calidad del rendimiento académico no se reduce al resultado de las calificaciones, factores personales (habilidades, actitudes y valores desarrollados por el estudiante) y sociales (familiares y estructurales), son destacados en este proceso. El papel de la mujer en el campo económico, su posición en el hogar ha contemplado grandes transformaciones: el cuidado de los hijos y la dedicación a actividades académicas que le permitan ser competitiva, solo para el trabajo, pero no para la educación y calidad del rendimiento de su hijo. Esta circunstancia influye en la modificación no solo de la familia sino también de la educación de los hijos (Sánchez, 2013).

Solano (2015), en el mismo sentido, explica el factor psicosocial. Las relaciones interpersonales, el ambiente familiar, escolar y social; la familia y su estructura básica, el nivel socioeconómico, el tipo de relaciones interpersonales, la presencia o no de situaciones críticas (enfermedades, paro, conflictos, divorcios, desamparo del hogar), el nivel de aspiraciones, el estado del bienestar y las expectativas son determinantes en el rendimiento.

En lo que concierne al sistema educativo, precisa:

La organización de la escuela, su infraestructura, la conducta del profesor, la actitud de los compañeros de clase, las expectativas de los profesores y de los alumnos, la aceptación, el rechazo y la popularidad en el grupo; los estilos educativos, la metodología, el sistema de evaluación y las características específicas de la institución educativa determinan el nivel del rendimiento. (Solano, 2015, p. 68)

El entorno social (influencia de los amigos, las redes sociales; el barrio, el vecindario) condicionan la calidad del rendimiento académico. La aceptación o rechazo del grupo o compañeros de clase es uno de los factores que más influencia ejerce en el rendimiento de manera positiva o negativa. El rechazo del grupo actúa como inhibidor de las propias capacidades. El grupo de amistades inclina al estudiante a seguir las tendencias del grupo. El tipo de actitudes, conductas y metas que tenga el grupo de amistades inclina a un lado u otro la balanza académica. 
Murillo (2013) propone los criterios para superar las deficiencias del rendimiento. Las competencias cognitivas, la motivación, el autoconcepto académico, el bienestar psicológico y la satisfacción, unidas a la asistencia a clases y la disciplina inciden en la calidad del rendimiento del estudiante. Acota también que el entorno familiar, el nivel educativo de la madre, el contexto socioeconómico, la complejidad del estudio, el ambiente escolar, las condiciones y servicios institucionales, así como la relación estudianteprofesor son determinantes en este proceso. Factores internos (espacio y tiempo) y externos (didácticos, metodológicos, necesidades e intereses de docentes y estudiantes) son generadores de la calidad del rendimiento del estudiante.

En lo que al factor metodológico se refiere, los estilos de aprendizaje, la administración del tiempo y de las habilidades personales; el apoyo de los compañeros, de la familia y de los profesores son grandes motivaciones. Las expectativas de los estudiantes son un indicador importante de éxito en el futuro académico. Está relacionado con la confianza en la inteligencia, pues promueve la lucha por altos promedios. Para que los estudiantes obtengan buenas calificaciones es necesario que estén satisfechos con las actividades que realizan, estas son experiencias positivas de aprendizaje y motivación. Asimismo, el estado de ánimo, el optimismo, la práctica de valores y entusiasmo son influyentes en el rendimiento académico; como también, el reconocimiento, las interacciones afectivas entre compañeros y docentes completan el circulo positivo de la calidad del rendimiento (Torres, 2011).

Con respecto, específicamente al rendimiento del estudiante universitario, Hernández resalta «el rendimiento académico como un factor imprescindible en el abordaje del tema de la calidad de la educación superior, debido a que es un indicador que permite una aproximación a la realidad educativa» $(2015$, p. 1370). Precisa que para alcanzar logros significativos se requiere de la interacción de factores personales (competencia cognitiva, autopercepción de capacidad y habilidades intelectuales, los altos niveles de energía y resistencia mental, el deseo de invertir esfuerzo en el trabajo que se está realizando, el entusiasmo, la inspiración, el sano orgullo, la automotivación hacia las tareas académicas, la asistencia a clases, mejoran los niveles de concentración y el rendimiento), y factores sociales-institucionales (la familia y la escuela: el afecto de los 
padres y de los docentes, el deseo del éxito, las expectativas académicas y la motivación). El tipo de universidad, los servicios ofrecidos por la universidad, el compañerismo, el ambiente académico, la formación del docente y condiciones económicas son también considerables en este proceso.

Las diferencias sociales y culturales, entorno familiar, nivel educativo de los progenitores o adultos responsables del estudiante, nivel educativo de la madre, contexto socioeconómico. Factores como la pobreza y la falta de apoyo social están relacionados con el fracaso académico. La influencia del padre y la madre influye significativamente en la vida académica. Un ambiente familiar propicio, marcado por el compromiso, una convivencia familiar democrática entre padres e hijos, los hábitos de trabajo, la orientación, las actividades culturales que se realizan, los libros que se leen, la estimulación para explorar y discutir ideas y acontecimientos y las expectativas sobre el nivel de estudios que pueden alcanzar los hijos, son factores importantes en una educación integral. El nivel educativo de los padres es determinante en el logro de resultados académicos positivos. Cuanto mayor sea el nivel académico de la madre, mayor percepción de apoyo hacia sus estudios tienen los hijos. (Hernández, 2015, p. 1374)

Hernández (2015), con respecto a los recursos didácticos agrega:

El acceso al internet, la literatura, relaciones familiares marcadas por el dialogo y la controversia propician el saber y resultados académicos positivos, sin embargo, el internet puede ser también causa de desigualdad: las personas que tengan mejor acceso y criterio de uso adecuado pueden prepararse mejor. (p. 1377)

Los factores institucionales, como la claridad e imparcialidad de las normas del reglamento, los servicios de calidad, un plan de estudios integrador y flexible y la sólida formación del profesorado, pueden facilitar el rendimiento. Los incentivos tales como becas, buena biblioteca, asistencia médica, apoyo psicológico refuerzan la respuesta del estudiante frente a los retos del estudio y mejoran el rendimiento. Tome nota: el estudiante busca 
siempre un profesor sabio (que domine su materia), que tenga buenas habilidades didácticas (que oriente el trabajo de modo efectivo y claro), pero al mismo tiempo, que inspire una buena relación afectiva (que brinde buen trato, que inspire respeto y disciplina, que sea un ejemplo) (Hernández, 2015).

\section{El comportamiento de excelencia}

La idea de que el buen comportamiento es efecto inmediato de la pedagogía del amor. El dicho nadie da lo que no tiene cobra importancia. Quien tiene afecto recibido de los padres y maestros eso es lo que da en su relación con los demás. Las experiencias más significativas se guardan en el inconsciente, el amor con todos sus detalles: buen trato, profundo respeto, consideración, valoración, queda en el alma, esculpido para siempre. El comportamiento es la exteriorización de lo que tenemos dentro, de lo que hemos recibido. Quien ha vivido valores en su vida, será capaz de dar, por el contrario, quien ha vivido violencia, maltrato, solo rebeldía puede dar. Lo bueno es que el comportamiento se puede formar. El buen ejemplo de los padres, de los maestros, de los amigos en interacción con el temperamento de cada uno y la sabiduría que se expresa en una educación integral, hacen que surja el buen comportamiento.

El comportamiento es la respuesta a una motivación en la que están involucrados componentes psicológicos, fisiológicos y motrices, y factores genéticos o hereditarios, situacionales o contextuales y personales. El ser humano siempre actúa llevado por preferencias, estímulos, intereses que le impulsan a realizar actos de acuerdo a su forma de ser y parecer. Se trata de la expresión del carácter, la personalidad y temperamento de cada quien. Expresa la continuidad de los fenómenos psíquicos, mostrando una singularidad en la manera de actuar y hacer, de cada uno. (Castillo \& Castillo, 2008, p. 20)

El autor prosigue, explicando lo que sucede con el comportamiento antisocial. Refiere a situaciones de mal comportamiento que generan irrupción, exigiendo un mayor control de la disciplina y el orden. Precisa que, las indisciplinas son conductas con mayor o menor dosis de violencia. 
La resistencia, el 'boicot' pasivo, el desafío y el insulto activo, puede desestabilizar la vida cotidiana. El 'bullying', proceso en el que uno o más alumnos acosan e intimidan a otro a través de insultos, rumores, vejaciones, aislamiento social es muy dañino para la convivencia. El maltrato intimidatorio tiene consecuencias devastadoras en víctimas y victimarios. (Castillo \& Castillo, 2008, p. 23)

Aseveran Castillo y Castillo (2008) que «el vandalismo y la agresión física son estrictamente fenómenos de violencia» (p. 24) contra la propiedad ajena y contra las personas. «El acoso sexual es una forma particular de bullying, la misma que implica maltrato de carácter racista o xenofóbico» (p. 26).

El grado de control influye e infunde determinados patrones en el comportamiento. El uso del poder (castigo físico, amenazas o privación de objetos) para hacer cumplir las normas, la retirada de afecto (ignorar al hijo, no hablarle, manifestándole su decepción o desaprobación) solo refuerzan el comportamiento negativo.

El alto nivel de comunicación entre padres e hijos, exige explicar las razones de las decisiones de los padres y el derecho a la opinión de los hijos. Imponer medidas, sin explicaciones razonables, muestra un bajo nivel de comunicación. En este sentido, el comportamiento de los padres puede ser autoritario o democrático. El primero, implica un alto nivel de control, de exigencia de madurez y bajos niveles de comunicación y muestras de afecto, y el segundo, se refiere al trato afectuoso, evitan el castigo, promueve altos niveles de comunicación y afecto, sensibilidad a las peticiones del hijo (no los caprichos). La deficiente comunicación y afecto forma hijos obedientes, ordenados, poco agresivos pero tímidos y tenaces en conseguir sus metas. Estos, son poco espontáneos, tienen bajo autoestima y son dependientes. Son limitados frente a las actividades autónomas, se muestran poco alegres, coléricos, infelices, fácilmente irritables y vulnerables frente a los desafíos. Por el contrario, la buena comunicación promueve exigencias de madurez e independencia. Los hijos formados según este estilo, tienen altos niveles de autocontrol y autoestima, iniciativa y confianza, son interactivos y hábiles en relacionarse con los demás. En lo que refiere al docente: 
La autoridad del docente ha perdido espacio y su sola presencia no es garantía de un buen comportamiento. Si el docente no es reconocido como autoridad, estará sujeto a que no se le respete e incluso se ponga en duda su capacidad para liderar el grupo de aprendizaje. Se exige un comportamiento democrático, donde la «autodisciplina» sea fruto del reconocimiento de derechos y deberes comunes. (Castillo \& Castillo, 2008, p. 27)

Por su parte, Tello (2017) precisa que el buen comportamiento siempre implica un sacrificio pero que a la larga tiene grandes beneficios: cada quien cosecha lo que siembra. El buen comportamiento de un estudiante produce una buena impresión en los profesores, administrativos y personas que observan. El docente, como consecuencia de buen comportamiento de sus estudiantes, habla bien de ellos, se siente orgulloso y los trata con más respeto. Por ello, conviene a todo estudiante, construir un historial limpio. Una conducta intachable, asegura las posibilidades de ser admitido en el trabajo, en los centros de estudio e instituciones. Una buena reputación determina la calidad del comportamiento.

La convicción de actuar siempre bien: el buen comportamiento lleva a la convivencia en todos los contextos (familia, universidad y sociedad). El cumplimiento de las normas fomenta el respeto, pero el buen comportamiento crea convivencia, trabajo armonioso y buen clima en el grupo humano. La puntualidad, el respeto a los derechos de cada uno y el cumplimiento de las obligaciones y responsabilidades son actitudes del buen comportamiento. Por el contrario, el comportamiento abusivo trae graves consecuencias. Los estudiantes maltratados muestran y adoptan diversas formas de conducta, tales como el miedo, que incapacita, crea desconfianza, inseguridad y vacilación; rigidez e inmovilidad del cuerpo. El comportamiento egoísta o el egocentrismo no permite conocer al mundo que nos rodea. El cultivo de la generosidad, el bien común y el trabajo en equipo, superan este problema. El comportamiento celoso trae sufrimiento, desasosiego, agresividad, llanto, aislamiento, reacciones negativas, incumplimiento y mecanismos de defensa (rebeldía, pataletas) para llamar la atención. 
Precisa Tello (2017), que el ejemplo es determinante. El comportamiento del padre influye en el hijo positiva y negativamente. La autoestima se deteriora, los intereses se desvanecen, los sentimientos y las motivaciones se destruyen. La forma del trato (con amor, paciencia, tiempo, prudencia, flexibilidad, oportunidad, son buenas estrategias para el buen comportamiento; por el contrario, el castigo promueve mal comportamiento. Es clave, buscar un modo adecuado para hacer entender al estudiante que cometió un error y que no debe volver a cometerlo. Es necesario un castigo proporcional al error cometido. Cuando un estudiante comete un error, es necesario hacerle comprender dónde está su error, ello ayudará mucho más que castigarlo, a superar el error y evitar que vuelva a cometerlo.

Tello (2017) termina de presentar su teoría del buen comportamiento dando al estudiante tips de comportamiento (Tabla 5).

\section{Tabla 5}

Tips para optimizar el comportamiento

\begin{tabular}{cc}
\hline & El buen comportamiento \\
\hline Tips & Estrategia \\
\hline
\end{tabular}

1. Escuchar siempre.

2. Poner atención a las explicaciones del profesor.

3. Seguir siempre las indicaciones del profesor.
1.1. Cuando el profesor habla en clase es importante asegurarse de escuchar.

1.2. Escuchar aunque no nos hablen directamente a uno.

1.3. Escuchar atentamente hace pensar al profesor que uno es un buen estudiante.

1.4. Escuchar, evitar pedir al profesor que vuelva a explicar lo que acaba de explicar con bastante detalle, podrías frustrarlo o molestarlo, en vez de eso, espera el momento oportuno para acercarte y expresarle tu necesidad de ayuda para entender mejor el tema.

2.1. Es una pésima costumbre, falta de responsabilidad, solidaridad y respeto, leer textos. Periódicos..., hablar con sus amigos y jugar en los celulares, cuando el profesor está hablando.

2.2. Si tienes trastorno por déficit de atención con hiperactividad u otra condición que te hace difícil la concentración, recuerda tomar tu medicamento, para que puedas prestar atención.

2.3. Evita en lo posible los distractores: la atención equivale al 30\% de la compresión de las clases.

3.1. A los docentes les agrada ver que sus alumnos los tratan con respeto.

3.2. Seguir todas sus indicaciones con atención ayuda a convertirse en una persona digna de confianza. 


\section{El buen comportamiento}

3.3. Seguir las indicaciones del docente respecto al ingreso y salida de los estudiantes durante las clases, al uso de los celulares durante la clase y la participación durante los debates.

3.4. Ser una persona que sigue las reglas con exactitud, expresa una imagen externa de ser una persona que cumple con las reglas.

4.1. Muchos estudiantes que no leen, frente a ello uno puede sacar ventaja de ellos al prestar más atención.

4. Leer detenidamente el programa del profesor y seguir cualquier instrucción especial que encuentres.

\section{Esforzarse por sacar} buenas notas.

\section{Participar en la} clase.

\section{Mantenerse tranquilo.}

4.2. A algunos profesores les gusta dar consejos reservados y difusos para ver quién escucha y quién no.

4.3. Si dice algo raro como 'asegúrense de estudiar este fin de semana', toma nota: podría estar planeando una prueba sorpresa para el día lunes.

4.4. Darás una excelente impresión si ya estás preparado.

5.1. Es importante demostrarle al profesor que se está dando lo mejor de sí.

5.2. Formula preguntas inteligentes durante la clase.

5.3. Si hay algo que se hace muy difícil de entender, es una buena estrategia, recurrir a la tutoría, asesoría o consejería del docente.

5.4. La disposición a buscar ayuda le muestra al profesor que el estudiante está tomando su clase con seriedad.

5.5. Un estudiante involucrado en el tema tiene mayores probabilidades de que se le considere favorablemente y se le de oportunidades.

5.6. Si el estudiante tiene problemas, debe preguntar al profesor para que le recomiende un tutor, no dude en preguntarle al profesor para que le recomiende un tutor.

5.7. Buscar ayuda en la necesidad es señal de madurez y la mayoría de los profesores consideran positiva dicha actitud por parte del estudiante.

6.1. Las clases siempre se centran en el diálogo entre el profesor y sus alumnos.

6.2. Responder las preguntas de la clase, aunque no se responda correctamente, muestra estar involucrado en el tema.

6.3. No participar es signo de no estar escuchando o indiferencia con el tema.

6.4. Es mejor levantar la mano cuando se quiere participar.

6.5. ¡Nunca sueltes las respuestas! Es fastidioso responder sin que el docente ceda la palabra.

7.1. Evitar las conversaciones para no interrumpir la clase, especialmente si el profesor está hablando.

7.2. Las interrupciones que se dan constantemente pueden molestar al profesor y puede sancionar.

7.3. Si uno no estás seguro de lo que va decir es mejor permanecer tranquilo 0 esperar que otro estudiante hable primero, y después evaluar la reacción de tu profesor. 


\section{El buen comportamiento}

\section{Tips}

Estrategia

8. Evitar hablar 0 mostrar gestos raros o sospechosos en la evaluación.

9. Siempre llegar a tiempo a la clase y no perder el tiempo en los pasillos.

10. Caerles en gracia a los administradores y autoridades de la institución educativa.

11. Evita las peleas.
8.1. Otros estudiantes podrían delatarte si los interrumpes o tratas de hacer trampa.

8.2. El docente puede sorprenderte y anular el examen.

8.3. Además de desaprobar el curso, construirás una mala reputación: plagiador.

9.1. Es natural saludar a cualquier amigo con el que te cruces, pero no te distraigas conversando más de lo necesario.

9.2. Llegar a tiempo a clase es signo de responsabilidad con los compromisos.

9.3. Controlar el tiempo permite hacer las cosas a tiempo.

9.4. Mantén el registro de tu tiempo y siempre deja suficiente tiempo para que llegues a la clase antes de que suene el timbre.

9.5. Los recreos pueden ser muy cortos, aunque no parezcan, y los estudiantes que llegan tarde siempre resultan perjudicados, pues se perdieron parte de la clase.

9.6. Llegar tarde constantemente, podría convertirse en motivo de alguna sanción o pérdida de las posibilidades de rendir eficientemente en los exámenes.

10.1. Las autoridades de la institución educativa son figuras no profesores, pero no significa que uno pueda ignorarlos. Cualquier trabajador es escuchado por el director y puede disciplinarte.

10.2. Ser respetuoso con las autoridades crea una buena reputación en el estudiante.

11.1. Algunas instituciones educativas tienen normas de tolerancia cero contra las peleas.

11.2. Tirarle un puñete a alguien podría terminar fácilmente en suspensión 0 expulsión.

11.3. Es mejor alejarse del peligro de la lista roja.

11.4. No meterse en peleas, salvo que sea absolutamente necesario para protegerse.

11.5. Incluso en casos urgentes en los que debes pelear, se corre el riesgo de meterse en un gran lío.

11.6. El mejor principio es evitar completamente las peleas.

11.7. Para lidiar con agresivos, es bueno saber que estos son personas débiles, inseguras, que hieren a otros para sentirse mejor ellos mismos.

11.8. Frente a los agresivos es mejor ignorar sus agresiones y comunicar lo sucedido al profesor 0 alguna autoridad de la institución educativa.

11.9. Si uno siente que se le está tomando de punto, comunicar al personal de la institución, para evitar las peleas.

11.10.Si lo hace, defiéndete, podrás decir que trataste de advertirles de antemano.

11.11. Nunca incites una pelea, sin importar cuán grosero sea alguien contigo, te llevarás la peor parte de la culpa si lanzas el primer puñete.

11.12.Si alguien te enfurece, usa tu inteligencia emocional para controlar tu temperamento y tus pasiones. 


\section{El buen comportamiento}

Tips Estrategia

12. No hables mal de nadie.

13. Trabajar por un historial limpio
12.1. El chisme es difícil de evitar divulgarlo, pero definitivamente debes evitarlo.

12.2. Rápidamente se corre la voz y si alguien escucha que uno ha dicho algo malo a espaldas de otro, rápidamente tendrás la reputación de ser una persona que no es digna de fiar.

12.3. Los rumores maliciosos sobre el personal de la escuela pueden poner tu trabajo en peligro.

12.4. Si uno es descubierto por iniciar un rumor, puede ser castigado severamente.

12.5. Antes de decir algo malo sobre alguien, reflexiona sobre si lo que dices es cierto 0 es solo un rumor, mejor, sé prudente.

12.6. Si es cierto, piensa cómo le haría sentir a esa persona escucharlo.

13.1. No todos los estudiantes tienen un historial de una conducta perfecta.

13.2. Si el pasado está manchado por el mal comportamiento, comienza inmediatamente a mejorar tu imagen.

13.3. Disculparse con los profesores, compañeros o administrativos a los que se les faltó el respeto.

13.4. Dedicar más tiempo a las tareas positivas, prestar atención en clase y no perderse ninguna indicación dada por el profesor.

Nota: Adaptado de Tello (2017, pp. 6-9). 
Finalmente, a los estudiantes que buscan tener un comportamiento de excelencia, Tello (2017), les sugiere estos tips:

\section{Tabla 6}

Tips para un comportamiento de excelencia

\begin{tabular}{cc}
\hline & Comportamiento de excelencia \\
\hline Indicador & Estrategia \\
\hline
\end{tabular}

1. Esforzarse al máximo.

1.1. Preocuparse por crear hábitos de estudio y cumplir con las horas de estudió diario que exigen las tareas académicas.

1.2. Hacer de la libertad una oportunidad para elegir lo que conviene a nuestro desarrollo y asumirlo con responsabilidad.

1.3. Matricularse en actividades extracurriculares: deportes, música, teatro.

1.4. Tener en mente que la universidad no se limita a la exigencia de una nota aprobatoria sino a preparar a las nuevas generaciones de profesionales, con «alto nivel académico, humano (...) y sólidos valores éticos» (Misión de la USMP).

1.5. Estudiar solo para el examen refleja el mínimo esfuerzo y el inicio de una vida mediocre.

2.1. Ser superficiales resta en vez de sumar. Uno es juzgado por su apariencia.

2. Cultivar una buena apariencia.

2.2. La buena reputación se gana vistiendo y arreglándose de la manera más pulcra y elegante.

2.3. Evitar la vestimenta extravagante, aretes 0 esas rarezas que la moda impone.

3.1. Llevar el rostro bien afeitado, el cabello y uñas recortados y limpios. Evitar morderse las uñas.

3. Mostrar una buena apariencia

3.2. Usar ropa adecuada y limpia, a la medida.

3.3. Usar una sobriedad inteligente en el uso del maquillaje.

4.1 Ello quita la sonrisa del rostro y muestra una apariencia amenazante o de matón.

4. Evitar el uso de piercings en el rostro 0 en el cuerpo.

4.2. La universidad no es un lugar para expresar las imposiciones de la moda, sino para desarrollar nuestra mente con miras a la excelencia profesional.

4.3. Tristemente, estos cambios en el aspecto físico son motivos para que algunas personas nos vean diferente.

5.1. Una buena manera de lograr una reputación es hacer todo lo posible para ser amable y cordial con los estudiantes que no son populares.

5. Hablar con las personas menos populares.

5.2. Sé voluntario para mostrarles los espacios, talleres y oficinas a los nuevos estudiantes.

5.3. Si ves que alguien se sienta solo, siéntate al costado y socializa con él. 


\section{Comportamiento de excelencia}

Indicador Estrategia

6. Rechazar enérgicamente el bullying.

7. Convertirse en un líder.

8. Dar ejemplo.

9. Mantener el buen comportamiento fuera de la institución educativa.

10. Ser voluntario activo en organizaciones benéficas.

11. Ignorar a los enemigos.
6.1. Es un acto honorable llevar a los excluidos a las actividades de grupo.

6.2. Hablar siempre de nuestras responsabilidades con el respeto a los derechos de las personas

6.3. Rechazar todo tipo de discriminación: color de la piel, raza, religión, sexo 0 situación social.

7.1. El papel de líder, otorga potencial para hacer algo bueno: buenas obras. Preséntate como candidato para delegado de aula o tercio estudiantil. Presenta tus propuestas de mejora, conviértete en la cabeza de todo proyecto.

8.1. El buen ejemplo permite ganarse el respeto y la admiración de todos: estudiantes y docentes ven un gran referente en las personas ejemplares.

8.2. El buen ejemplo crea relaciones de confianza y solides en las relaciones sociales.

9.1. Las palabras corren muy rápido en la institución educativa: lo que uno haga fuera de la institución educativa puede afectar la manera en que uno es visto dentro de ella.

9.2. Actuar con coherencia tanto dentro como fuera de la institución. Evitar la tara de la doble personalidad: donde hay control buena gente y donde no hay control mala gente.

10.1. Participar en programas y actividades comunitarias. Sé guía de los jóvenes que están en riesgo.

10.2. Anima a tus amigos a hacer lo mismo.

10.3. Tales actitudes contribuyen a cultivar una honorable y buena imagen pública.

11.1. El ser buenas personas provoca envidias y celos en los demás: se consciente de ello.

11.2. Ignora cualquier burla o insulto que venga de los envidiosos.

11.3. Mostrar madurez y control.

11.4. Evita rebajarte al nivel de tus enemigos. No devolver sus propios insultos.

11.5. Lo importante es vivir la felicidad de comportarse bien.

11.6. Ojo: si uno se porta bien y luego se porta mal, los demás quedan muy decepcionados.

Nota: Adaptado de Tello (2017, pp. 6-9). 


\section{Conclusiones}

Alcanzado nuestro objetivo principal que fue determinar la influencia de la pedagogía del amor y la PNL en la formación integral de la persona, y su rol determinante en la calidad del rendimiento académico y el comportamiento, concluímos que la pedagogía del amor tiene un efecto significativo en la calidad del rendimiento académico y el comportamiento y por ende en la formación integral de la persona humana.

La pedagogía del amor es la expresión práctica de los valores humanos, principalmente del amor. La familia, el docente y los nuevos aportes de la ciencia de la mente (PNL) son fundamentales en la consecución de los fines de la pedagogía del amor y la formación integral de la persona. El presente estudio va dirigido a los padres de familia, docentes e investigadores, instándolos a seguir investigando sobre el significado y valor del amor en la formación integral de los hijos, estudiantes y ciudadanos.

Finalmente, esta investigación pretende motivar al docente a que incluya en su práctica pedagógica y en su vida, la pedagogía del amor y las estrategias de la PNL, considerando que de ellas dependen la calidad del rendimiento académico y el comportamiento, expresiones de una educación integral.

\section{Referencias}

Aguilera, M. A., \& Martínez, V. A. (2017). La Pedagogía del Amor al interior de cuatro instituciones educativas de Bogotá D. C. «Una expedición inmarcesible». Bogotá: Fundación Universitaria los Libertadores.

Alarcón, R. (2009). Psicología de la Felicidad: Introducción a la psicología positiva. Rev. De psicología PUCP, $28,252$.

Amaya, C., \& Martínez, J. (2011). La programación neurolingüística aplicada al mejoramiento de los procesos internos de comunicación en el consultorio odontológico. Bogotá: Odont express center, Universidad de la Salle.

Argyle, M. (1992). La Psicología de la Felicidad (Traducción de Gonzales C.). Barcelona: Alianza Editorial.

Bandler, R., \& Grinder, J. (2004). La Estructura de la Magia II (The Structure Magic). Cambio y congruencia (7 Ed.). Traducción de Elena Olivos María E. Viveros. Santiago de Chile: Cuatro vientos. Recuperado de http:/l www.avapsi.es/media/com_lazypdf/pdf/LEDLM2.pdf

Bloom, B. (1997). Características Humanas y Aprendizaje. Bogotá: Voluntad.

Bloudani, D. (2015). La Programación Neurolingüística como estrategia de diagnóstico en el rendimiento de alumnos en educación primaria. Puerto de la Cruz: Universidad de La Laguna. 
Castillo, I., \& Castillo, I. (2008). Aplicación de un plan de acción «vivamos en armonía» utilizando estrategias afectivas en el mejoramiento del comportamiento escolar de los/as estudiantes del primer grado de secundaria de la IE Javier Pérez de Cuéllar del Asentamiento Humano Villa Primavera, Sullana (Tesis de maestría). Universidad de Piura, Piura. Recuperado de: http://iraceniaeisabelcastillo.blogspot.com/

Cerezo, M. (2014). Habilidades sociales. Propuesta. Valladolid: Universidad de Valladolid.

Cortez, G., \& Narciza, G. (2015). Estrategias pedagógicas de Programación Nuerolingüística y su relación con la enseñanza de Lengua y Literatura en los sextos y séptimos años de las escuelas de la parroquia Augusto $N$. Martínez del cantón Ambato en el año 2013. (Tesis de maestría). Pontificia Universidad Católica del Ecuador, Departamento de Investigación y Posgrados. Recuperado de http://repositorio.pucesa.edu.ec/handle/ $123456789 / 1476$

De Zubiría, M (2007). Introducción a pedagogía conceptual. Bogotá: Fundación Internacional de Pedagogía Conceptual Alberto Merani. Recuperado de http://psicoanalisiscv.com/wp-content/uploads/2012/03/ MIGUELDEZUBIRIA-afetividad-y-pedagog\%C3\%ADa1.pdf

De Zubiría, J. (2013). El maestro y los desafíos a la educación en el siglo XXI. Bogotá: REDIPE 825

Díaz, G., \& Salamanca, N. (2013). La pedagogía del afecto. Una mirada al contexto escolar de la Institución Educativa Distrital Fe y Alegría. Bogotá: San Ignacio.

Faulkner, W. (1940). Las palmeras salvajes (Traducción de Jorge Luis Borges). Buenos Aires: Sudamericana.

Gardner, H. (2000). La educación de la mente y el conocimiento de las disciplinas. Barcelona: Paidós Ibérica.

Gardner, H. (2001). Estructuras de la Mente: La teoría de las inteligencias múltiples. Bogotá: Fondo de Cultura Económica.

Goleman, D. (1996). La inteligencia emocional. Barcelona: Kairós.

Hernández, C. A. (2015). Diagnóstico del rendimiento académico de estudiantes de una escuela de educación superior en México. Revista UCM: Instituto Politécnico Nacional. México. Recuperado de http:/l revistas.ucm.es/index.php/RCED/article/view/48551/48839. 1369-1388.

Jarife, A., \& Pomares, M. (2011). Programación Neurolingüística. ¿Realidad o Mito en Psicología y Ciencias Cognitivas? Revista de la Facultad de Ciencias de la Salud, 2, 243-250.

Korzybski, A. (1933). Manhood or Humanity y Science and Sanity (La Semántica en general). I.G.S. Englewood, New Jersey: Traducción de Ramiro J. Álvarez Fernández.

Leuridan, J. (2018). El sentido de las dimensiones éticas de la vida ( $2^{\mathrm{a}}$ Ed.). Lima: USMP.

Marina, J. A. (1996). El Laberinto Sentimental. Barcelona: Anagrama.

Mena, T. (2013). Factores afectivos que inciden en el aprendizaje de una lengua extranjera: la motivación. Oviedo: Universidad de Oviedo.

Méndez, M. C. (2014). La Pedagogía del afecto. Bogotá: WE.ORG.

Ministerio de Educación del Perú. (2017). Currículo Nacional de Educación Básica. Lima: Minedu.

Montenegro, W. (2016). Saber estudiar con las técnicas y estrategias del Método Holístico y la PNL: Saber estudiar es la clave para obtener resultados exitosos. Revista Cultura, 30, 173-224.

Murillo, E. G. (2013). Factores que inciden en el rendimiento académico en el área de matemáticas de los estudiantes del noveno grado en los centros de educación básica de la ciudad de Tela. Honduras: Atlántida, Universidad Francisco Morazan.

O’Connor, J., \& Seymour, J. (1992). Introducción a la Programación Neuro-Lingüística. Barcelona: Ediciones Urano.

Olguin, D. (2014). La Pedagogía del afecto. Madrid. Recuperado de http://danielolguin.com.ar/?p=1803 
Palmero, M. L. (2010). La teoría del Aprendizaje Significativo en la perspectiva de la teoría cognitiva. Barcelona: Octaedro.

Pérez, D. D., Betancourt, E., \& Silveira, Y. (2015). La pedagogía afectiva: un desafío en la educación superior ecuatoriana. Riobamba: Universidad Nacional del Chimborazo.

Piaget, J. (1999). Psicología de la inteligencia. México: Booket.

Pontificio Consejo para la Justicia y la Paz. (2004). Compendio de la Doctrina Social de la Iglesia. Madrid: BAC.

Proyecto Aldea Educa. (2013). Pedagogía del afecto. Paraguay. Recuperado de http://www.fundacionalda.org/ mm/file/biblio_recursosdidacticos_sustentos/13_Pedagogia_Afecto.pdf

Rodríguez, M. L. (2010). La teoría del aprendizaje significativo en la perspectiva de la psicología cognitiva. Barcelona: Octaedro.

Saavedra, L. (2010). La pedagógica afectiva como método de enseñanza-aprendizaje en la facultad de Derecho y Ciencias Sociales. Universidad de Michoacan de San Nicolás de Hidalgo, Michoacan. Recuperado de http://psicopedagogiaxico.blogspot.com/2014/11/

Sambrano, J. (1997). PNL para todos. Caracas: Alfadil.

Sánchez, I. (2013). Apoyo parental y rendimiento académico (Tesis de maestria). Universidad Autónoma de Tamaulipas, México. Recuperado de http://bibliotecadigital.tamaulipas.gob.mx/archivos/descargas/ 7983545d502dfa507ae1275a57a61368af287051.pdf

Savater, F. (1997). El Valor de Educar (8 ${ }^{\mathrm{a}}$ Ed.). Barcelona: Ariel.

Solano, L. O. (2015). Rendimiento académico de los estudiantes de secundaria obligatoria y su relación con las aptitudes mentales y las actitudes ante el estudio (Tesis doctoral). UNED. Recuperado de http://espacio.uned.es/fez/eserv/tesisuned:Educacion-Losolano/Solano_Luengo_Luis_Octavio.pdf

Steiner, C. (2011). Educación emocional. Teoría de caricias. Sevilla: Jeder.

Tello, M. (2017). Los niños dicen cómo comportarse correctamente en clases. Recuperado de http:/l www.panorama.com.ve/pitoquito/Los-ninos-dicen-como-comportarse-correctamente-en-clases-201604120089.html; http://es.wikihow.com/portarse-bien-en-la-escuela

Torres, R. M. (5 de marzo de 2011). Pedagogía del afecto. Diario la capital, Rosario. Recuperado de http:/l www.oeaservicioseducativos.com/\#!/-pedagogia-del-afecto/

Vanga, M. G., \& Fernández, A. (2015). Gerenciando el aula con herramientas PNL. Una guía para la comunicación eficaz. Aracaju, Brasil: $4^{\circ}$ Congreso Iberoamericano en Investigación Cualitativa.

Vanga, M. G., \& Fernández, A. (2016). Programación Neurolingüística para fomentar la dirección afectiva, creatividad y comunicación en el aula. Revista AUC, 37, 43-50. Recuperado de http://editorial.ucsg.edu.ec/ ojs-auc/index.php/auc-ucsg/article/download/6/6

Yepes, J. C. (2016). ¿Qué son los anclajes en PNL? Recuperado de http://blogs.portafolio.co/negocios-einspiracion/los-anclajes-pnl/ 